\title{
PRECISE COMPLEX MICRO-TEXTURING INTO STAINLESS STEELS BY PLASMA PRINTING
}

Cite as: 11th Proceedings of SEATUC Symposium, Ho Chi Minh City University of Technology, 1-8 (2017)

Published Online: 14 March 2017

Hengky Herdianto, Tatsuhiko Aizawa, Kenji Wasa, Dionisius Johanes Djoko Herry Santjojo, Setyawan Purnomo Sakti

Identifier:

DOI https://doi.org/10.31219/osf.io/m6xnj 


\title{
PRECISE COMPLEX MICRO-TEXTURING INTO STAINLESS STEELS BY PLASMA PRINTING
}

\author{
Hengky Herdianto ${ }^{(1)}$, Tatsuhiko Aizawa ${ }^{(2)}$, Kenji Wasa ${ }^{(3)}$, \\ D.J. Djoko H. Santjojo ${ }^{(4)}$, Setyawan P. Sakti ${ }^{(5)}$ \\ ${ }_{(1,4,5)}$ University of Brawijaya, Indonesia \\ ${ }^{(2)}$ Shibaura Institute of Technology, Japan \\ ${ }^{(3)}$ TECDIA, Co., Ltd, Japan \\ Email: hengkyherdianto@gmail.com
}

\begin{abstract}
The plasma printing was used to make precise micro-texturing into the stainless steels to have complex textured geometry. First in this plasma printing, the original two dimensional micro-patterns were drawn onto the substrate surface by the maskless patterning with use of the nano-carbon ink. These micro-patterned specimens were further plasma-nitrided at $673 \mathrm{~K}$ for $5.4 \mathrm{ks}$ by $70 \mathrm{~Pa}$ with use of the hollow cathode device. The unprinted surface areas were selectively nitrided to have high nitrogen solute contents up to 12 mass $\%$. The masked area just corresponded to the carbon-mapping from the printed nano-carbon inks, while the unprinted surface, to the nitrogen mapping. The hardness profile had stepwise change across the borders between these printed and unprinted areas; e.g., the hardness on the unprinted surface was $1200 \mathrm{Hv}$ while it remained to be $350 \mathrm{Hv}$ on the printed surface. This selective nitriding accompanied with the selective hardening. This selective nitriding enabled us to construct the three dimensionally textured miniature dies and products by chemical etching of the printed area.
\end{abstract}

KEYWORDS: Plasma printing, Maskless patterning, Stainless steels, Selective nitriding, Selective hardening

\section{INTRODUCTION}

Micro- and nano-textures on the metal and polymer surfaces of parts and components have functions to reduce the friction and wear in (Etsion, 2004) and to improve the joining strength in (Aizawa, 2014a). As needed, the surface texturing is also employed to have the surface profile leather-touched or textile-patterned. In order to fabricate these micro- and nano-textured surface of products, the mold for precise injection molding or the dies for fine stamping must have their original micro- and nano-textures on their surfaces. In (Aizawa, 2014b), (Aizawa, 2015), (Katoh, 2015), and (Aizawa, 2016), the non-traditional processing was proposed to make micro-texturing into dies and molds with aid of the high density plasma nitriding.

In this plasma printing, the original two dimensional micro-pattern is directly drawn onto the mold and die surfaces. This printed mold and dies are subjected to the plasma nitriding by using the printed area as a mask. Since the masked area is free from the plasma nitriding, the unmasked or unprinted area is selectively plasma nitrided and hardened. The masked or printed area, which has much lower hardness than the nitrided area, is mechanically removed by the blasting or brushing method to finish the micro-textured mold and die surfaces. Different from the micro-milling and microEDM, no CAM data or no tools are necessary to make micro-texturing. Tedious and time-consuming milling and electric discharging processes are saved to fabricate the molds for injection molding in much shorter processing time. In those previous works, the size of micro-pattern in width was limited by 50 to $100 \mu \mathrm{m}$; the possibility of fine micro-texturing by the plasma printing must be demonstrated with use of the well-aligned micro-patterns.

In the present paper, the maskless pattering with aid of the lithography is utilized to draw the initial micropatterns onto the stainless steel specimen and molds. These substrates are plasma nitrided at $673 \mathrm{~K}$ to demonstrate their unprinted surfaces are selectively nitrided and hardened. The contour of the nitrogen mapping just corresponds to the initial micro-pattern; the printed micro-patterns on the substrate are textured into the stainless steels as a high content nitrogen solute map. 


\section{EXPERIMENT}

\subsection{Plasma printing}

The plasma printing consists of two steps. In the first step, the initial two dimensional micro-patterns are drawn onto the stainless steel specimen and molds. The high density plasma nitriding is employed for selective nitrogen concentration into their unprinted part. Figure 1 summarizes the experimental set-ups for these two processes.

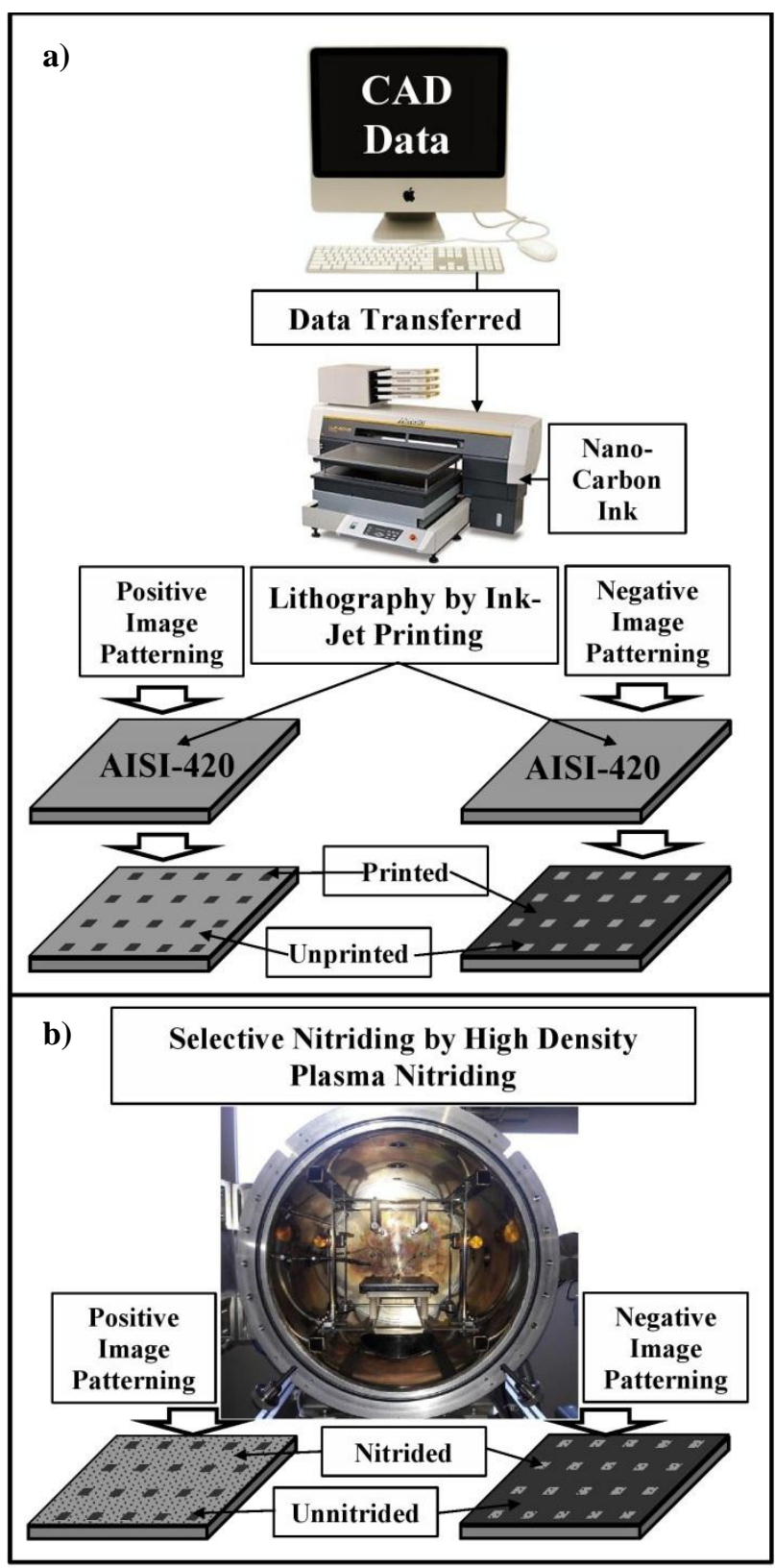

Fig. 1. Experimental setup for the plasma printing.

a) Maskless patterning by lithography, and, b) High density plasma nitriding.
In the former, the initial micro-patterns are built up into the CAD data; every tailored micro-pattern is drawn with the nano-carbon ink. In the latter process, the unprinted substrate surface is selectively nitrided by the high density plasma nitriding with use of the drawn micro-patterns as a mask.

\subsection{Maskless patterning with use of nano-carbon ink}

The maskless micro-patterning method by the lithography was utilized to draw the initial two dimensional micro-patterns directly onto the stainless steel substrate surface. Figure 2 depicts a typical micropattern drawn on the stainless steel sheet with use of the nano-carbon ink. Even when using the same CAD data for micro-patterning, there are two manners in drawing: the positive-image drawing as depicted in Figure 2a) and $2 \mathrm{c}$ ), and the negative-image drawing as shown in Figure $2 b)$ and 2d). Both images are complementary to each other. Besides for the lines, the letters and the microdots, the micro-nozzle head shapes are drawn on the sheet specimens and the mold samples.

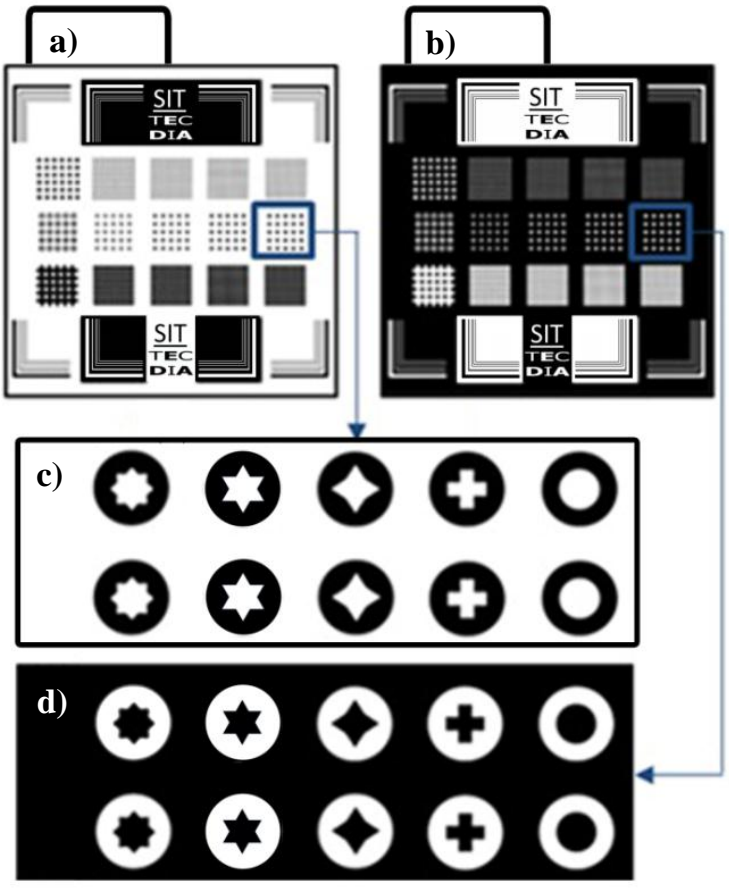

Fig. 2. Micro-patterning onto the stainless sheet surface.

a) Positive image patterning, b) Negative image patterning, c) Positive image of nozzle heads, and, d) Negative image of nozzle heads.

At present, the drawing area is limited by $25 \times 25$ $\mathrm{mm}^{2}$ with the spatial resolution down to $1 \mu \mathrm{m}$. No masks are used in this approach. Various kinds of micro-units with the geometric complexity is straight forwardly designed by CAD and drawn on the AISI420 substrates. This maskless micro-patterning is useful to draw any designed micro-head pattern with the complex geometries and within the high spatial resolution. 


\subsection{Plasma nitriding system}

High density plasma nitriding system was set-up for selective nitriding and hardening of stainless steels. Different from the PECVD (Plasma Enhanced Chemical Vapor Deposition) or DC-pulse nitriding, where the plasmas are ignited and generated in the frequency of 13.56 $\mathrm{MHz}$ or its multiples, the present high density nitriding system has no mechanical matching box with slow response time of $1 \mathrm{~s}$ to $10 \mathrm{~s}$ to adjust the applied power. Since both the input and output powers are automatically matched by frequency adjustment around 2 $\mathrm{MHz}$, the matching response time is only limited to $1 \mathrm{~ms}$ at most. This prompt power control provides to make full use of mesoscopic plasma pressure range over $50 \mathrm{~Pa}$.

Different from the conventional processes, the vacuum chamber is electrically neutral so that RF-power and DC-bias should be controlled independently from each other. A dipole electrode is utilized to generate RFplasma; DC bias is directly applied to the specimens. Heating unit is located under this DC-biased cathode plate. In the following nitriding experiments, the specimens are located on the cathode table before evacuation down to the base pressure of $0.1 \mathrm{~Pa}$.

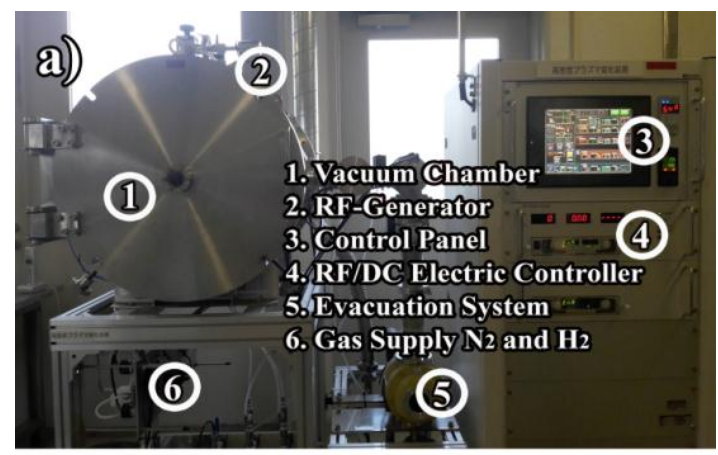

b)

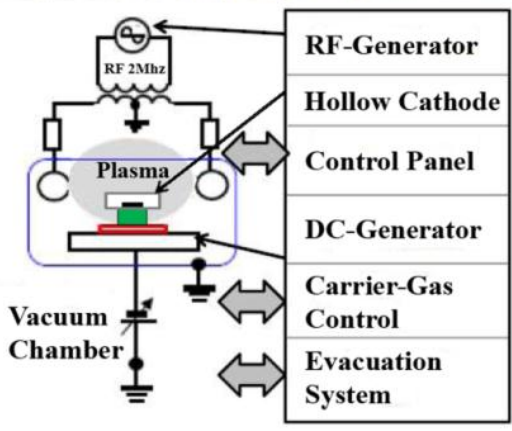

Fig. 3. RF/DC plasma nitriding system. a) outlook of system, and, b) schematic illustration of system.

Then, nitrogen gas is first introduced as a carrier gas for heating. After heating to the specified holding temperature, the nitrogen pre-sputtering is started at the constant pressure. After pre-sputtering, the hydrogen gas is added to nitrogen gas with the specified partial pressure ratio. Both pressure $(P)$ and temperature $(T)$ controls are automatically performed with the tolerance of $\Delta P<1 \mathrm{~Pa}$ in deviation of partial pressure and $\Delta T<1$ $\mathrm{K}$ in temperature fluctuation.

Table 1. Plasma nitriding conditions for plasma printing of test pieces.

\begin{tabular}{|l|l|}
\hline \multicolumn{1}{|c|}{ Process } & \multicolumn{1}{|c|}{ Parameters } \\
\hline Pre-sputtering & DC (500 V), RF (0 V) \\
& Pressure (70 Pa) \\
& Temperature $(673 \mathrm{~K})$ \\
& Duration (1.8 ks) \\
& Carrier gas ( $\mathrm{N}_{2}$ only) \\
\hline Nitriding & DC $(500 \mathrm{~V}), \mathrm{RF}(250 \mathrm{~V})$ \\
& Pressure (70 Pa) \\
& Temperature $(673 \mathrm{~K})$ \\
& Duration $(14.4 \mathrm{ks})$ \\
& Carrier gas $\left(\mathrm{N}_{2}+\mathrm{H}_{2}\right)$ \\
& Partial pressure $\left(\mathrm{N}_{2}=160 \mathrm{~mL} / \mathrm{min} ;\right.$ \\
& $\left.\mathrm{H}_{2}=30 \mathrm{~mL} / \mathrm{min}\right)$ \\
\hline
\end{tabular}

Table 2. Plasma nitriding conditions for plasma printing of mold-die micro-patterns specimen.

\begin{tabular}{|l|l|}
\hline \multicolumn{1}{|c|}{ Process } & \multicolumn{1}{|c|}{ Parameters } \\
\hline Pre-sputtering & DC (450 V), RF (0 V) \\
& Pressure (70 Pa) \\
& Temperature (Room standart) \\
& Duration (400 s) \\
& Carrier gas ( $\mathrm{N}_{2}$ only) \\
\hline Nitriding & DC (300 V), RF $(250 \mathrm{~V})$ \\
& Pressure (70 Pa) \\
& Temperature $(673 \mathrm{~K})$ \\
& Duration $(5.4 \mathrm{ks})$ \\
& Carrier gas $\left(\mathrm{N}_{2}+\mathrm{H}_{2}\right)$ \\
& Partial pressure $\left(\mathrm{N}_{2}=100 \mathrm{~mL} / \mathrm{min} ;\right.$ \\
& $\left.\mathrm{H}_{2}=20 \mathrm{~mL} / \mathrm{min}\right)$ \\
\hline
\end{tabular}

After nitriding, the unprinted area in Figure 2 is expected to be nitrided while the printed area in Figure 2 is free from nitriding and remains as before.

\subsection{Test-pieces}

AISI420 specimens were prepared for description of the plasma nitriding behavior with use of the masking technique. A rectangular sample with $20 \times 10 \times 2 \mathrm{~mm}^{3}$, was commonly used to measure the hardness depth profile in the nitrided specimen. A masked sample by the carbon tape was also employed to prove that unmasked part of AISI420 surface was selectively nitrided by the present method.

\subsection{Mold-die specimen}

Both the positive and negative images were drawn on the AISI420 mold specimens. Two types of specimens were prepared for description of the plasma nitriding behavior and for micro-texturing; e.g., thin AISI420 sheets with $25 \times 25 \times 1 \mathrm{~mm}^{3}$, and, the mold-die specimen with $25 \times 25 \times 5 \mathrm{~mm}^{3}$. 


\subsection{Observation and measurement}

The plasma condition was observed and identified by using the optical emissive-light spectroscopy (EOS; PMA-11, Hamamatsu, Co. Ltd). SEM (Scanning electron microscope; Shimadzu, Corp) was used to observe the change of printed mask pattern before and after nitriding. EDX (Energy Dispersive X-ray; SSX-550, Shimadzu, Co. Ltd.) was utilized to analyze the nitrogen content distribution at the vicinity of the border between the printed and unprinted surface. The hardness of nitride specimen was measured by Vickers micro-hardness testing (Mitsutoyo, Co. Ltd) while XRD (Smartlab, Rigaku, Co., Ltd.) was used for analyzing the microstructure of specimen.

\section{EXPERIMENTAL RESULTS}

\subsection{Optimization in the plasma nitriding}

Through the quantitative plasma diagnosis, the generated species in the plasmas are detected and monitored by EOS. Figure 4 shows an emissive light spectrum measured in the plasmas for nitriding with and without use of the hydrogen gas. $\mathrm{NH}$ radicals as well as the activated nitrogen atom and molecules are detected in both spectra. With use of the mixed nitrogen and hydrogen gases, every peak intensity is enhanced even with a little addition of hydrogen gas.

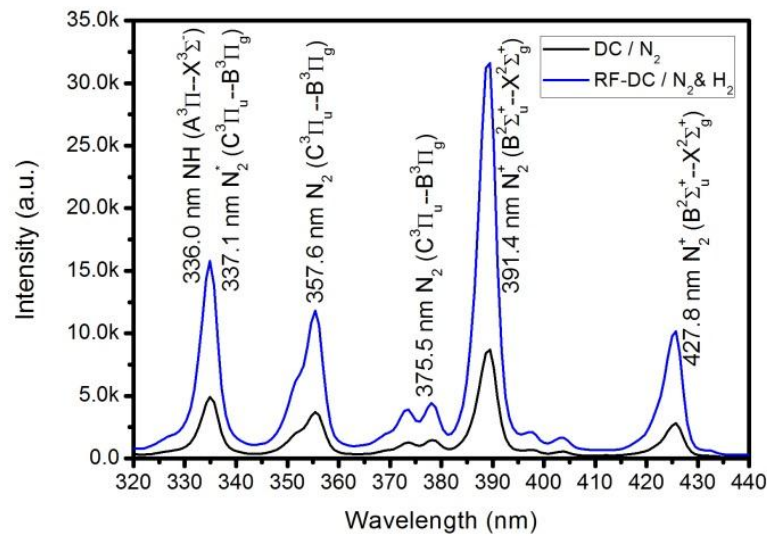

Fig. 4. The emissive light spectra of plasmas with and without addition of hydrogen gas.

$\mathrm{NH}$ radicals are detected at $\lambda=336.0 \mathrm{~nm}$ as reported in (Choi, et al., 2005) together with $\mathrm{N}_{2}{ }^{*}$, at $\lambda=337.1 \mathrm{~nm}$ in (Suraj, et al., 2007). This significant population of $\mathrm{NH}$ radicals and $\mathrm{N}_{2}{ }^{*}$ might be responsible for high infiltration of nitrogen atoms into the stainless steels. The other species were detected are $\mathrm{N}_{2}$ (at $357.6 \mathrm{~nm}$ and $375.5 \mathrm{~nm}$ ) and $\mathrm{N}_{2}^{+}$(at $391.4 \mathrm{~nm}$ and $427.8 \mathrm{~nm}$ ) after (Suraj, et al., 2007).

\subsection{Solid solution by high density plasma nitriding}

After (Aizawa, 2016), no nitrides were synthesized in the lower temperature plasma nitriding; the nitrogen atoms were present as a solute in the $\mathrm{Fe} / \mathrm{Cr}$ lattices by occupying their vacancy sites. This nitrogen solid solution process plays a key to make selective nitrogen mapping only into the unprinted surface area in Figure 2 without the formation of nitrides. Those nitrides might hinder the homogeneous nitrogen solid solution in local on the unprinted surface.

XRD analysis was performed to investigate whether the iron and chromium nitrides were precipitated by plasma nitriding at $673 \mathrm{~K}$ for $5.4 \mathrm{ks}$ for AISI420 sheet-sample, and $14.4 \mathrm{ks}$ for AISI420 specimens, respectively. No formation of nitrides was detected in Figure 5. Besides for the original $\alpha^{\prime}-\mathrm{Fe}$ peak at $2 \theta=$ $44.7^{\circ}$, two new peaks were detected around $40^{\circ}<2 \theta<$ $45^{\circ}$. The first peak was detected at $2 \theta=43.52^{\circ}$, and, the second peak, at $2 \theta=41.44^{\circ}$. These two peaks are related to the extended martensitic lattice by high nitrogen extraordinary solid solution just as stated in (Aizawa, 2016) and (Farghali, 2016). After (Istiroyah, 2016), the first peak corresponds to the expanded martensite $(\alpha-$ $\mathrm{Fe}(\mathrm{N}))$ where the nitrogen solute occupies the vacancy sited in $\alpha-F e$ lattice.

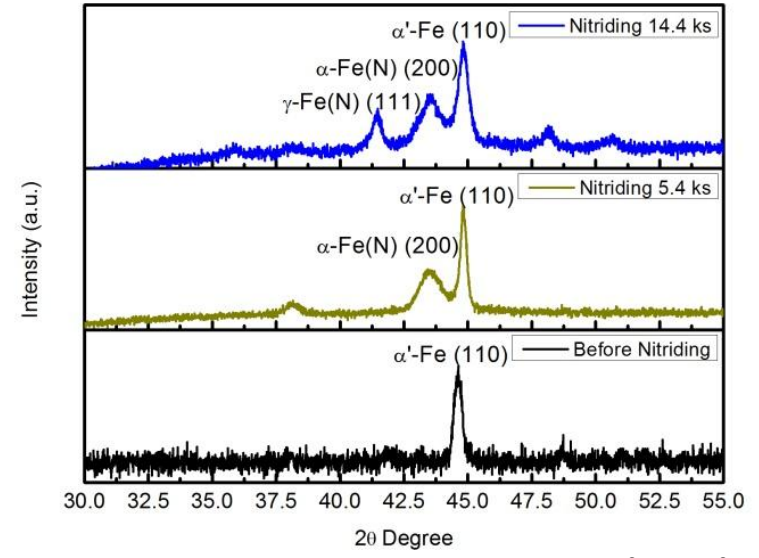

Fig. 5. XRD diagrams in the $2 \theta$-range from $30^{\circ}$ to $55^{\circ}$ for the untreated AISI420 and the nitrided AISI420 samples for $5.4 \mathrm{ks}$ and $14.4 \mathrm{ks}$.

The second peak was present after higher nitrogen concentration for $14.4 \mathrm{ks}$; both the large lattice expansion and anisotropic internal strain in this high nitrogen concentration, induce the phase transformation from martensitic lattice ( $\alpha$ '-Fe) through the expanded phase of $\alpha-\mathrm{Fe}(\mathrm{N})$ into the austenitic $\gamma-\mathrm{Fe}(\mathrm{N})$ lattice with the significantly large peak shift from $44.78^{\circ}$ to $41.44^{\circ}$ as corresponding to (Farghali, 2016). This finding is also consistent with the results reported by (Istiroyah, 2016) and (Manova, et al., 2006). This XRD demonstrates that nitrogen atoms are present as a solute in the $\mathrm{Fe} / \mathrm{Cr}$ lattice of AISI420 stainless steel sheets and molds with high content.

\subsection{Selective nitriding}

Geometry and dimensions are observed and measured by SEM after ink jet printing and plasma nitriding in the present plasma printing. 

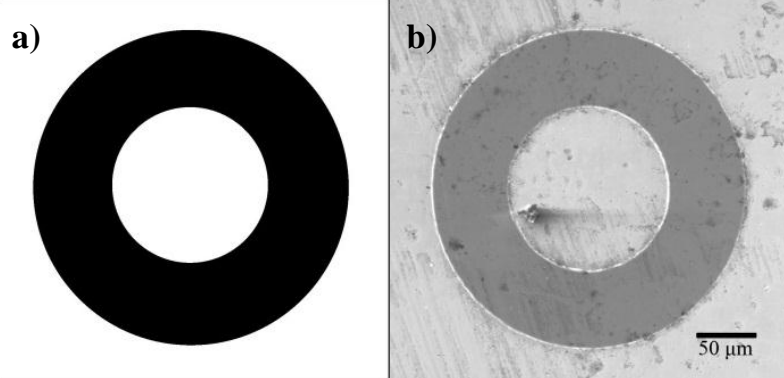

Fig. 6. Micro positive circular model and its printed pattern on the AISI420. a) CAD data for a single micro positive circular model, and (b) Printed micro positive circular model onto the AISI420.

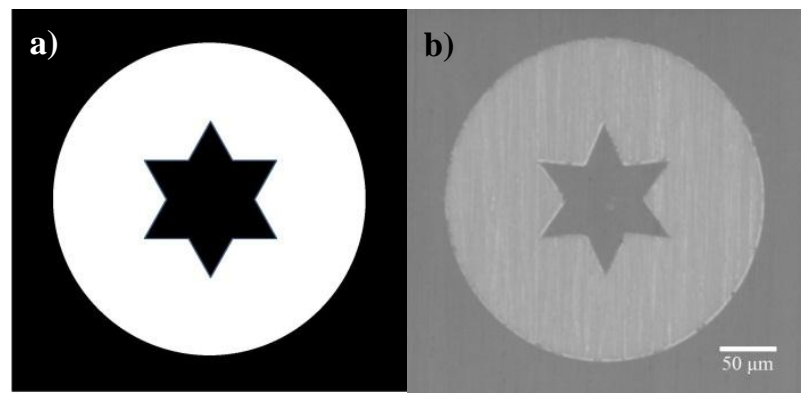

Fig. 7. Micro negative circular star model and its printed pattern on the AISI420. a) CAD data for a single micro positive circular star model, and (b) Printed micro positive circular star model onto the AISI420.

Table 3. Elements of AISI420 micro-patterns onto unprinted surface after nitriding

\begin{tabular}{|l|c|c|}
\hline Elements & \multicolumn{2}{|c|}{$\begin{array}{c}\text { Kind of micro-patterns design } \\
\text { mass } \%\end{array}$} \\
\hline Carbon & 2.6 & $\begin{array}{c}\text { Negative Image } \\
\text { mass\% }\end{array}$ \\
\hline Nitrogen & 12.2 & 2.0 \\
\hline Silicon & 0.8 & 10.7 \\
\hline Phosphorus & 0.3 & 0.9 \\
\hline Sulphur & 0.2 & 0.3 \\
\hline Chromium & 12.1 & 0.2 \\
\hline Manganese & 2.3 & 12.0 \\
\hline Iron & 68.8 & 2.0 \\
\hline Nickel & 0.8 & 0.3 \\
\hline
\end{tabular}

Energy Dispersive X-ray analysis was utilized to describe the nitrogen content distribution at the vicinity of the border between the unprinted surface. Table 3 shows presentation of nitrogen distribution of positive and negative micro-patterns onto AISI420 surface. The unprinted surface areas in the nitrided micro-texture were selectively nitrided to have high nitrogen solute contents up to 12 mass \% in the case of the positive-image and 10 mass\% contents in the case of negative image. As depicted in Figure 8 and 9, the nitrogen maps selectively on the unprinted surface area both in the positive and negative images. No nitrogen is present on the printed areas. On the other hand, the carbon from the ink maps only on the printed surface area in both images. This exclusive carbon-nitrogen mapping proves that only the unprinted parts of substrate should have high content nitrogen solutes.

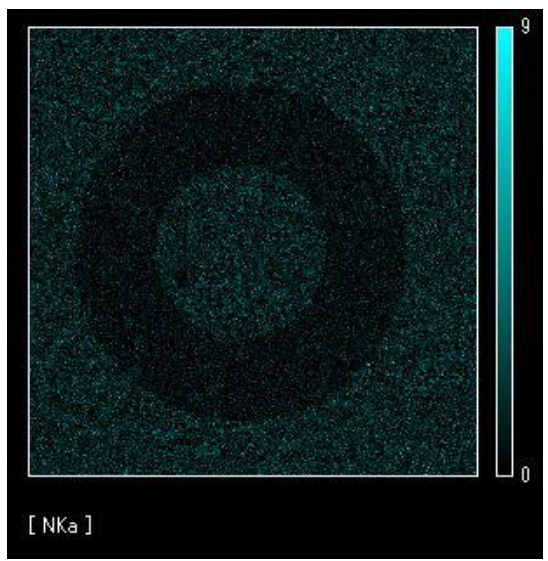

Fig. 8. Nitrogen distribution of micro-patterns positive circular model onto the AISI420 surface after nitriding.

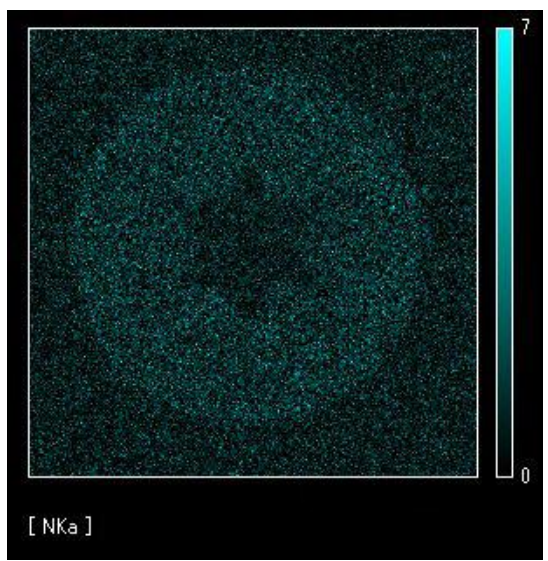

Fig. 9. Nitrogen distribution of micro-patterns negative circular star model onto the AISI420 surface after nitriding process.

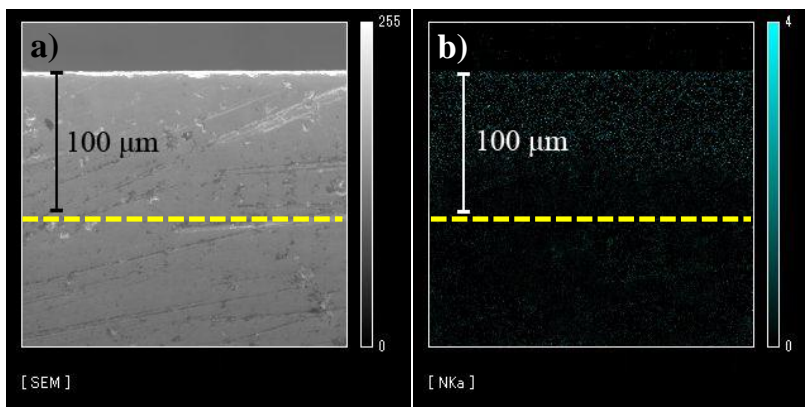

Fig. 10. SEM image and nitrogen mapping by EDX on the cross-section AISI420. a) SEM image on the on the cross-section of nitrided layer AISI420, and, b) nitrogen mapping by EDX in Figure 10a. 


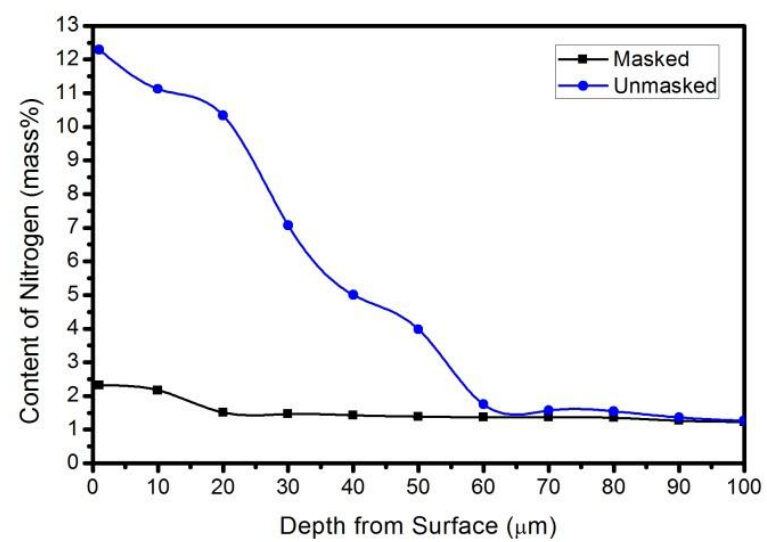

Fig. 11. Distributions of nitrogen solute in the depth from the surface of the masked and unmasked region on the cross-section.

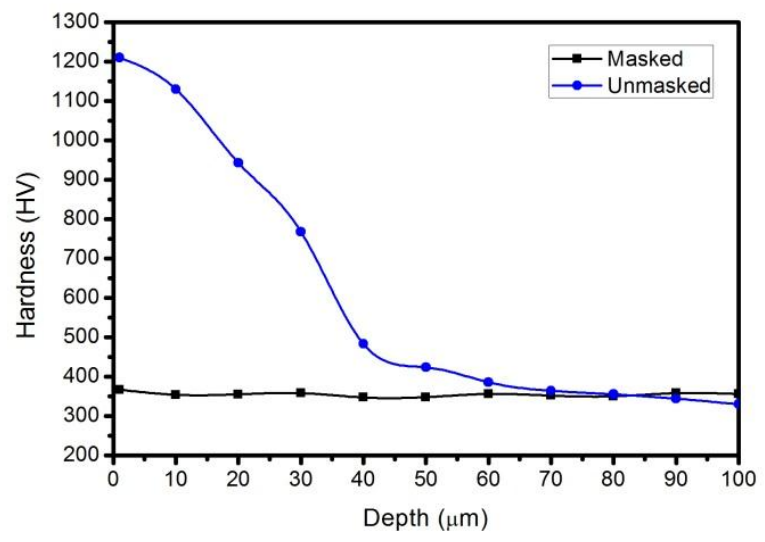

Fig. 12. Hardness depth profiles of the masked and unmasked region on the cross-section.

Scanning Electron Microscope (SEM) as well as Electron Diffraction X-ray (EDX) were utilized to make micro-structure analysis and to make nitrogen element mapping on the cross-section of nitrided specimens. Micro-Vickers hardness testing was performed to describe the surface hardness distribution as well as the hardness depth profile. The applied load was constant by $0.50 \mathrm{~N}$ (or $50 \mathrm{~g}$ ).

A typical scanning electron microscopy (SEM) from cross section of plasma nitrided sample is shown in Figure 10a). Figure 10b) show concentration depth profiles of nitrogen elements mapping measured by Energy Dispersive X-ray (EDX) on samples plasma nitrided at $673 \mathrm{~K} 70 \mathrm{~Pa}$. Figure 11, concentration of the nitrogen near the surface reached up to 12 mass $\%$ and decreased drastically at a depth of $60 \mu \mathrm{m}$ with a nitrogen solute contents down to 1.7 mass $\%$.

Decreasing of nitrogen concentration has an impact to hardness reduction. Figure 12 shows hardness depth profiles of the masked and unmasked region on the cross-section. The hardness that near surface reached up to $1210 \mathrm{Hv}$ and while it remained to be $386 \mathrm{Hv}$ at a depth of $60 \mu \mathrm{m}$ from surface.

\subsection{Selective hardening}

Figure 13b depicts the measured micro-Vickers hardness profile along the scanning yellow line in Figure 13a. The measured hardness is nearly equal to the original matrix hardness of $350 \mathrm{Hv}$ in the masked regions of specimen surface. The average hardness reaches 1390 $\mathrm{Hv}$ in the un-masked or the nitrided regions. A sharp change in hardness from $350 \mathrm{Hv}$ up to $1390 \mathrm{Hv}$ is detected in Figure 10b across the border between the masked and un-masked regions. The masking pattern changes itself onto the hardness pattern on the stainless steel substrate by this plasma nitriding.

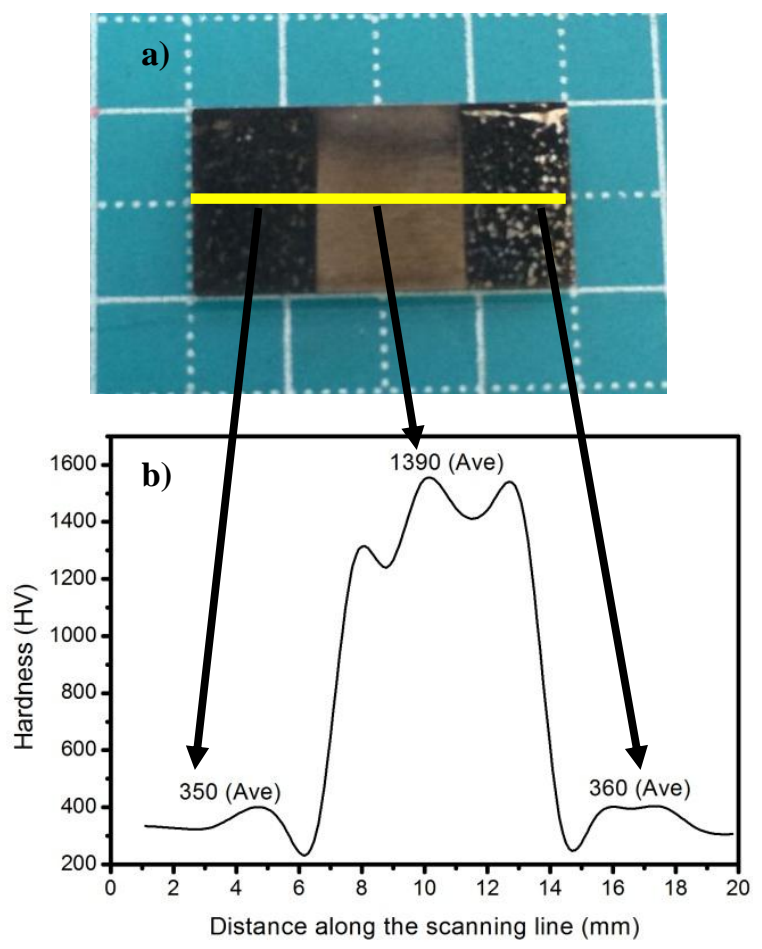

Fig. 13. Hardness measurement of masked and unmasked AISI420 after plasma nitriding for $14.4 \mathrm{ks}$ at $673 \mathrm{~K}$. a) sample after polishing, and, b) measured hardness profile along the yellow scanning line in Figure 13a.

The hardness profile was measured along a single yellow scanning horizontal line across the circular and circular star pattern between the printed and unprinted regions. In order to demonstrate that the original printed pattern should be homogeneously transformed into the hardness profile pattern, a single square region was only left unprinted at the center of AISI420 specimen as shown in Figure 14a) and Figure 14b). 

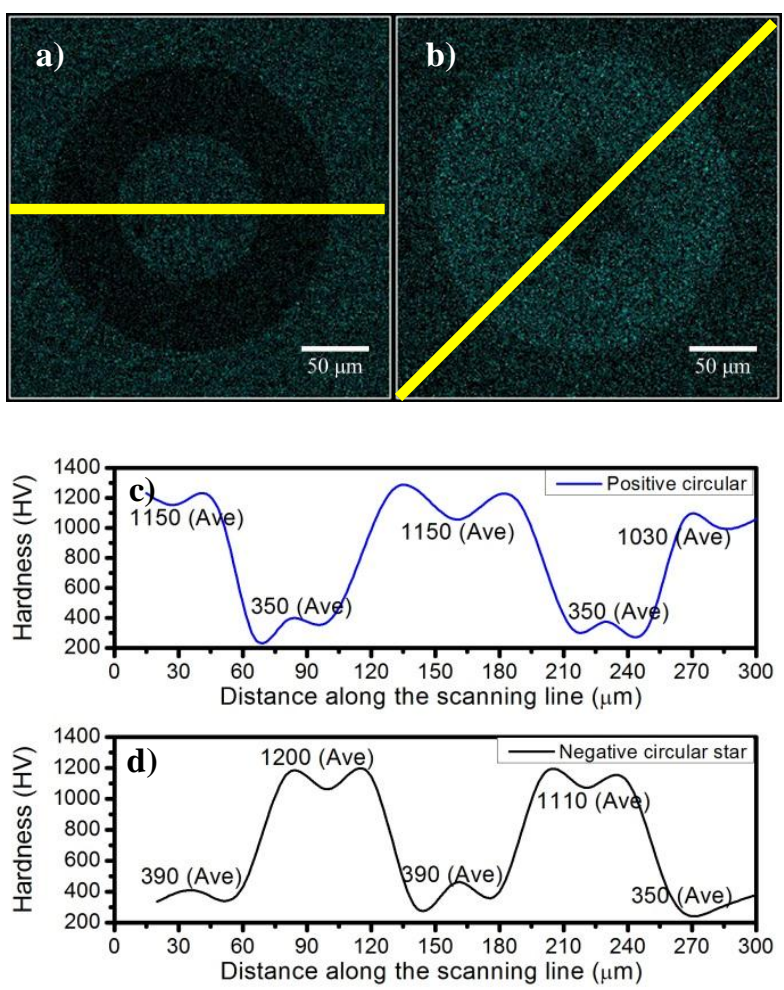

Fig. 14. Transformation of two dimensional micropatterns to the hardness profile by the present plasma printing for $5.4 \mathrm{ks}$ at $673 \mathrm{~K}$. a) micro-patterns positive circular model onto the AISI420 surface after nitriding, b) micro-patterns negative circular star model onto the AISI420 surface after nitriding, c) measured hardness profile along the yellow scanning horizontal line in Figure 14a, and, d) measured hardness profile along the yellow scanning diagonal line in Figure 14b.

Figure 14c) and Figure 14d) compares the hardness profiles measured both in the lateral and longitudinal directions across the mask. Less significant difference was seen in both hardness profiles; i.e. the hardness in the un-printed regions is $1200 \mathrm{Hv}$, and, it remains to be $350 \mathrm{Hv}$ in the printed region. The steep change of hardness across the edge of masks reveals that the unprinted regions are nitrided to have much higher hardness than matrix hardness of AISI420 stainless steels. The printed regions are free from infiltration of nitrogen atoms into matrix.

\section{CONCLUSIONS}

The plasma printing consists of the initial two dimensional micro-patterning onto the stainless steel specimen and molds and the high density plasma nitriding. Through optimization of the nano-carbon ink contents, the printed patterns have sufficient heat resistivity even during plasma nitriding at at $673 \mathrm{~K}$ for 5.4 ks by $70 \mathrm{~Pa}$ with use of the hollow cathode device. These two peaks are related to the extended martensitic lattice by high nitrogen extraordinary solid solution. Both the large lattice expansion and un-isotropic internal strain in this high nitrogen concentration induces the phase transformation from martensitic lattice $\left(\alpha^{\prime}-\mathrm{Fe}\right)$ through the expanded phase of $\alpha-\mathrm{Fe}(\mathrm{N})$ into $\gamma-\mathrm{Fe}(\mathrm{N})$ lattice with the significantly large peak shift from $44.78^{\circ}$ to $41.44^{\circ}$.

The unprinted surface areas were selectively nitrided to have high nitrogen solute contents up to 12 mass\%. The masked or printed area, which has much lower hardness than the nitrided area. The hardness on the unprinted surface was $1200 \mathrm{Hv}$ while it remained to be $350 \mathrm{Hv}$ on the printed surface. The selective nitriding enabled us to construct the three dimensionally textured miniature dies and products by chemical etching of the printed area.

\section{REFERENCES}

Aizawa, T., Satoh, S., and Yamaguchi, T., Microtexturing design for joining between polymer components, Proc. $7^{\text {th }}$ ICOMM, vol. 15, pp. 1-9, 2014 a.

Aizawa, T., and Yamagichu, T., High-density plasma nitriding assisted micro-texturing onto martensitic stainless steel mold-die, Proc. $9^{t h}$ IWMF, vol. 12, pp. 55-61, 2014b.

Aizawa, T., Suga, H., and Yamaguchi, T., Plasmanitriding assisted micro-texturing into stainless steel molds, Proc. MATEC, vol. 21, pp. 1-6, 2015.

Aizawa, T., Fukuda, T., and Morita, H., Low temperature high density plasma nitriding of stainless steel molds for stamping of oxide glasses, J. of Мапи. Rev., vol. 3, pp. 5-11, 2016.

Choi, Y., et al., Characteristics of atmospheric pressure $\mathrm{N}_{2}$ cold plasma torch using $60-\mathrm{Hz}$ AC power and its application to polymer surface modification, $J$. of Surf. \& Coat. Tech., vol. 193, pp. 319-324, 2005.

Etsion, I., Improving tribological performance of mechanical components by laser surface texturing, $J$. of Tribo. Lett., vol. 17, pp. 733-737, 2004.

Farghali, A.M., and Aizawa, T., Strain induced phase transformation from martensitic to austenitic phases by nitrogen solid solution, Proc. $10^{\text {th }}$ SEATUC, (Tokyo) (CD-ROM), 2016.

Istiroyah., Wardana, I.N.G., and Santjojo, D.J.D.H., Effect of hydrogen addition on the characteristics of nitrided martensitic stainless steel AISI 420, J. of App. Mech. \& Mate., vol. 836, pp. 214-218, 2016.

Katoh, T., Aizawa, T., and Yamaguchi, T., Plasma assisted nitriding for micro-texturing onto martensitic stainless steels, J. of Manu. Rev., vol. 2, pp. 2-8, 2015.

Manova, D., et al., Variable lattice expansion in martensitic stainless steel after nitrogen ion implantation, J. of Nucl. Inst. \& Meth. in Phys. B, vol. 242, pp. 285-288, 2006.

Suraj, K.S., et al., Near cathode optical emission spectroscopy in $\mathrm{N}_{2}-\mathrm{H}_{2}$ glow discharge plasma, J. of Surf. \& Coat. Tech., vol. 202, pp. 301-309, 2007. 


\section{PHOTOS AND INFORMATION}

Hengky Herdianto received the
S.Pd. (2014) degree in Physics
from State University of
Surabaya, Indonesia. He is a
postgraduate student, Department
of Physics, University of
Brawijaya, Indonesia. His current
interests include nano-micro
fabrication, multifunctional metal
complexes, and plasma physics.

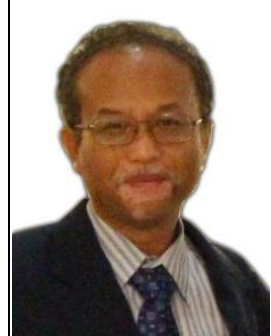

Setyawan P. Sakti received the Drs. (1989) degree in Physics from Gadjah Mada University, Indonesia, M.Eng (1994) degree in Sensor Science and Engineering from University of South Australia, and Dr.-Ing (2000) degree in Sensor and Micro System from Magdeburg University, Germany. $\mathrm{He}$ is a lecturer, Department of Physics, University of Brawijaya, Indonesia. His research interests cover sensor technology, plasma technology, instrumentation and measurement. 